\title{
Association between tea and coffee consumption and brain cancer risk: an updated meta-analysis
}

\author{
Yang Song ${ }^{1}$, Zhiyun Wang ${ }^{1 *}$, Yanyu $\mathrm{Jin}^{2}$ and Jie Guo
}

\begin{abstract}
Background: Previous studies had demonstrated some associations between coffee and tea consumption and brain cancer risk resulted in an inconsistent relationship. We therefore performed this study to further explore the association between them.

Method: By searching PubMed, Embase, and Web of Science, we retrieved up to 1 November 2018, 11 relevant literature of publications were collected by 2 people eventually. Stata 14.0 software was used for data analysis.

Results: In total, 11 articles (11 articles for coffee, 8 articles for tea, and 4 articles for coffee plus tea) were used in this meta-analysis. A statistically significant protective effect of coffee consumption and brain cancer risk was found $\left(\mathrm{RR}=0.785,95 \% \mathrm{Cl}=0.580-0.984, P^{2}=65.6 \%, P\right.$ for heterogeneity $\left.=0.001\right)$, especially in Asian populations $(\mathrm{RR}=0.217$, $95 \% \mathrm{Cl}=0.042-0.896)$. However, the association between the risk of brain cancer and tea consumption was nonsignificant in the whole result $\left(\mathrm{RR}=0.897,95 \% \mathrm{Cl}=0.739-1.088, P^{2}=29.9 \%, P\right.$ for heterogeneity $\left.=0.189\right)$, but significant in American populations ( $R R=0.798,95 \% \mathrm{Cl}=0.646-0.986)$. Interestingly, the $\mathrm{RR}$ was $0.684(95 \% \mathrm{Cl}=0.481-0.975)$ for the risk of brain cancer when compared the highest versus the lowest category consumption of coffee plus tea.

Conclusion: Findings from this study suggested that higher consumption of coffee may contribute to the lower development of brain cancer in Asian populations. Tea consumption had an inverse association for the risk of brain cancer in American populations, instead of other populations.
\end{abstract}

Keywords: Coffee, Tea, Brain cancer, Glioma, Meta-analysis

\section{Introduction}

Brain cancer is one of the most common malignant tumors in adult primary intracranial tumors $[1,2]$. The role of several nutritional factors in the prevention of brain cancer has been investigated. For example, consumption of fresh fruits and vegetables [3], fresh fish [4], and vitamin supplements [5-7] have been acted preventive agents. Coffee and tea are popular with people as two kinds of drinks. Coffee consumption had been linked to some cancers. Horisaki et al. performed a dose-response meta-analysis indicated that coffee consumption may be weakly inversely associated with the risk of colorectal cancer in Japanese [8]. Previous studies

\footnotetext{
* Correspondence: wang_zhy@yeah.net

'Department of Neurology, Tianjin First Center Hospital, No. 24, Fukang Road, Nankai District, Tianjin 300192, China

Full list of author information is available at the end of the article
}

published by Lukic et al. [9] and Lafranconi et al. [10] suggested that a prospective effect of coffee consumption on the risk of endometrial cancer. Highest versus lowest category of tea consumption had been confirmed of decreased with liver cancer [11, 12], ovarian cancer [13], gastric cancer [14], oral cancer [15, 16], and endometrial cancer [17].

A previous meta-analysis was published to explore the association between coffee and tea consumption and the risk of glioma in adults [18]. They concluded that the highest versus lowest category of coffee consumption, tea consumption, and coffee plus tea consumption had no effect on the risk of brain cancer. However, many studies had been published to further assess the association between coffee and tea consumption and the risk of brain cancer since that meta-analysis. For this reason, this paper increased the sample size and improved the

(C) The Author(s). 2019 Open Access This article is distributed under the terms of the Creative Commons Attribution 4.0 International License (http://creativecommons.org/licenses/by/4.0/), which permits unrestricted use, distribution, and 
test efficiency through an updated meta-analysis to obtain more authentic and reliable analysis results, which is helpful to clarify whether coffee or tea consumption has some inverse effects on brain cancer development, and finally provides evidence of prevention for brain cancer.

\section{Methods}

\section{Search strategy and inclusion criteria}

Two authors independently checked the databases of PubMed, Embase, and Web of Science to find the relevant articles which investigated the association between tea and/or coffee consumption and risk of brain cancer from inception up to 1 November 2018. The following search terms were used: "tea" OR "coffee" OR "drinking" combined with "brain cancer" OR "brain tumor" OR "glioma." To identify titles and abstracts of relevant literature, reference lists of studies were checked manually.

All studies included in this meta-analysis should meet the following criteria: (1) assessment of the tea and/or coffee consumption and brain cancer or glioma risk; (2) observational studies; (3) the detailed data of studies must be completely provided in all participants directly or indirectly; (4) human studies.

\section{Data extraction}

Data were extracted independently by two researchers (YS and ZYW). All the information listed in Table 1 in each study was abstracted carefully. The disagreements with these two researchers were resolved by discussion and consensus.

\section{Statistical analysis}

Stata 14.0 software was used for data analysis. The combined relative risk (RR) with its $95 \%$ confidence interval (CI) for tea and coffee consumption and brain cancer risk were calculated. Forest plots for the association between tea and coffee consumption and brain cancer risk were mapping. Heterogeneity between studies was evaluated by chi-square-based $Q$ test and $I^{2}$ test $[19,20]$. The random-effects model was used for all the analysis. Potential publication biases were examined using Egger's linear regression [21] and Begg's funnel plots [22]. Sensitivity analysis was done to estimate the stability of the results by removing a single study from the analysis. Subgroup analyses by study design and geographic location were also performed. $P<0.05$ was considered statistically significant.

\section{Results}

\section{Study selection and study characterization}

According to retrieval methods above, 2421 relevant studies from the databases (671 articles from PubMed, 1299 articles from Web of Science, and 451 articles from
Embase) and 2 additional records identified when we reviewed the discussion and introduction of the included studies were selected. In total, 11 articles [23-33] were included in this study, as shown in Fig. 1. Six studies were from the USA, 1 from Australia, 1 from Canada, 1 from Iran, 1 from Japan, and 1 from Europe (France, Italy, Spain, Denmark, Germany, Greece, Netherlands, Norway, Sweden, and the UK). Eight of the 11 included studies were cohort design, and the remaining 3 studies were case-control design. The characteristics of the observational studies are shown in Table 1.

\section{Coffee consumption and the risk of brain cancer}

All of the 11 included studies were used to assess the association between coffee consumption and brain cancer risk. Pooled RR suggested that highest category of coffee consumption could reduce the risk of brain cancer $(\mathrm{RR}=$ $0.785,95 \% \mathrm{CI}=0.580-0.984, I^{2}=65.6 \%, P$ for heterogeneity $=$ 0.001) (Fig. 2), when compared with the lowest category. Ten of the 11 included studies were performed about coffee consumption and glioma risk, resulting in a statistically significant protective effect of coffee consumption on the risk of glioma ( $R R=0.760,95 \% \mathrm{CI}=0.548-0.972$ ). This result is showing a statistically significant protective effect of coffee consumption in the cohort studies $(\mathrm{RR}=$ $0.858,95 \% \mathrm{CI}=0.700-0.992$ ), instead of case-control studies. Furthermore, we also explored whether the risk of brain cancer was related to geographic location. The results from our analysis indicated that an inverse association was only found in Asian populations $(R R=0.217$, $95 \% \mathrm{CI}=0.042-0.896$ ), but not in other populations else. Table 2 shows the results for both whole and subgroup analyses.

Based on Egger's test $(P=0.214)$ and funnel plot (Additional file 1: Figure S1), there existed no publication bias. Sensitivity analysis was done, and the pooled RR ranged from $0.738(95 \% \mathrm{CI}=0.542-0.961)$ to 0.905 $(95 \% \mathrm{CI}=0.754-1.088)$.

\section{Tea consumption and the risk of brain cancer}

Eight articles [24, 25, 27, 29-33] were included to explore the relationship between tea consumption and brain cancer risk. Our meta-analysis result showed that there was a non-significant association between tea consumption and brain cancer risk $(\mathrm{RR}=0.897,95 \% \mathrm{CI}=$ $0.739-1.088, I^{2}=29.9 \%, P$ for heterogeneity $\left.=0.189\right)($ Fig. 3 ). Seven of the eight included studies were about tea consumption and glioma risk. The result was consistent with the brain cancer $(\mathrm{RR}=0.846,95 \% \mathrm{CI}=0.683$ 1.047). We conducted a subgroup analysis by study design (cohort studies and case-control studies). The association was non-significant in prospective studies or in case-control studies. However, when we further explored the association between brain cancer and geographic 


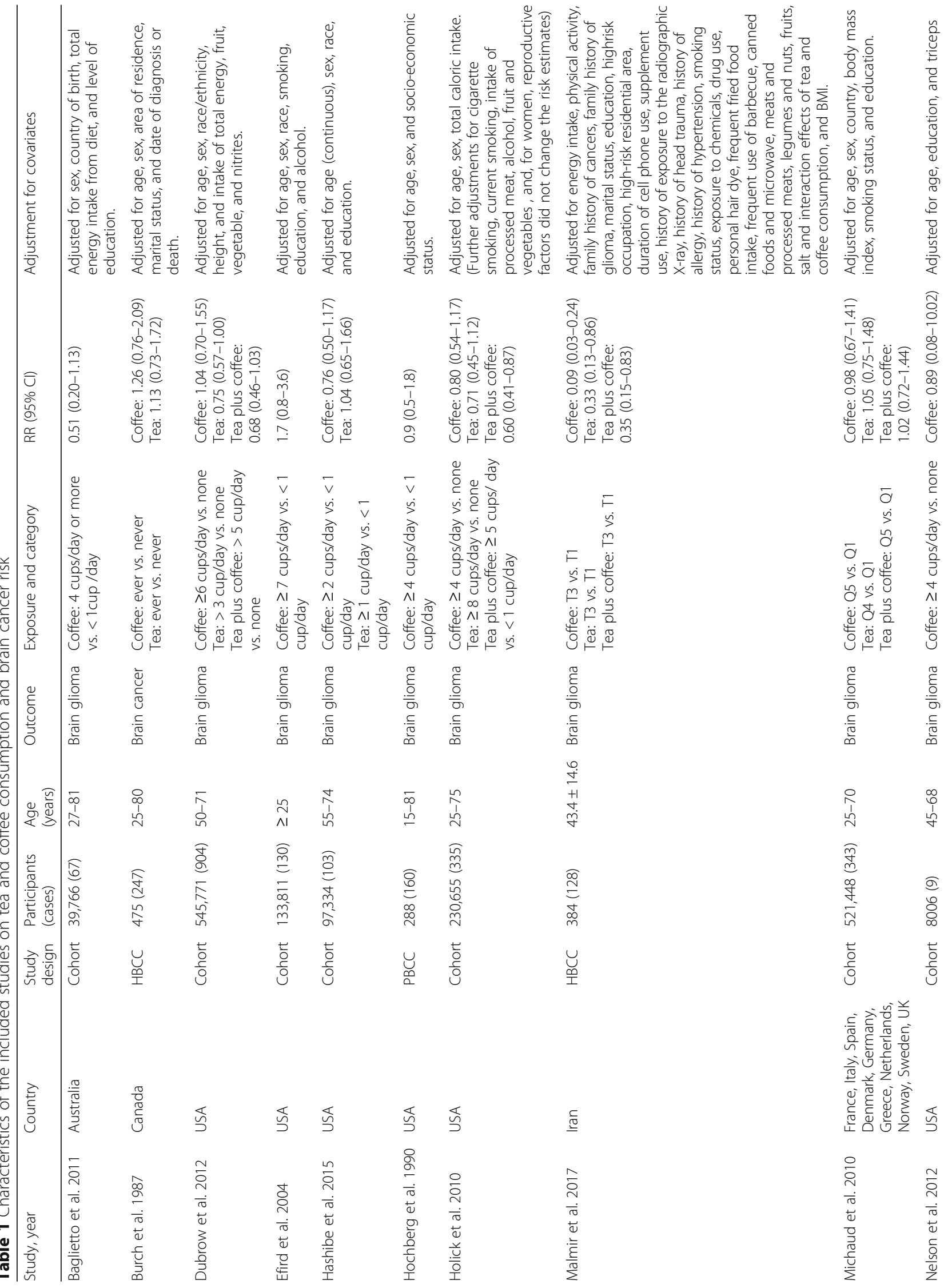




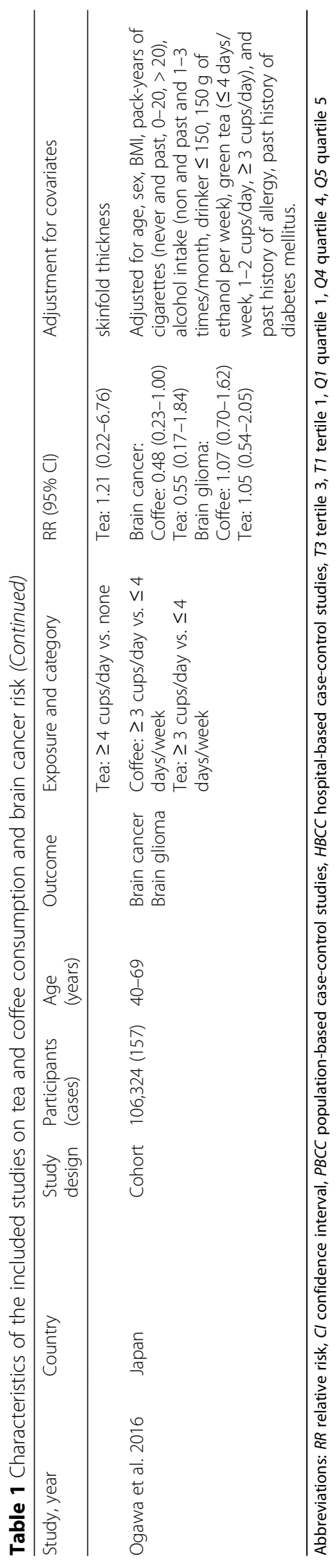




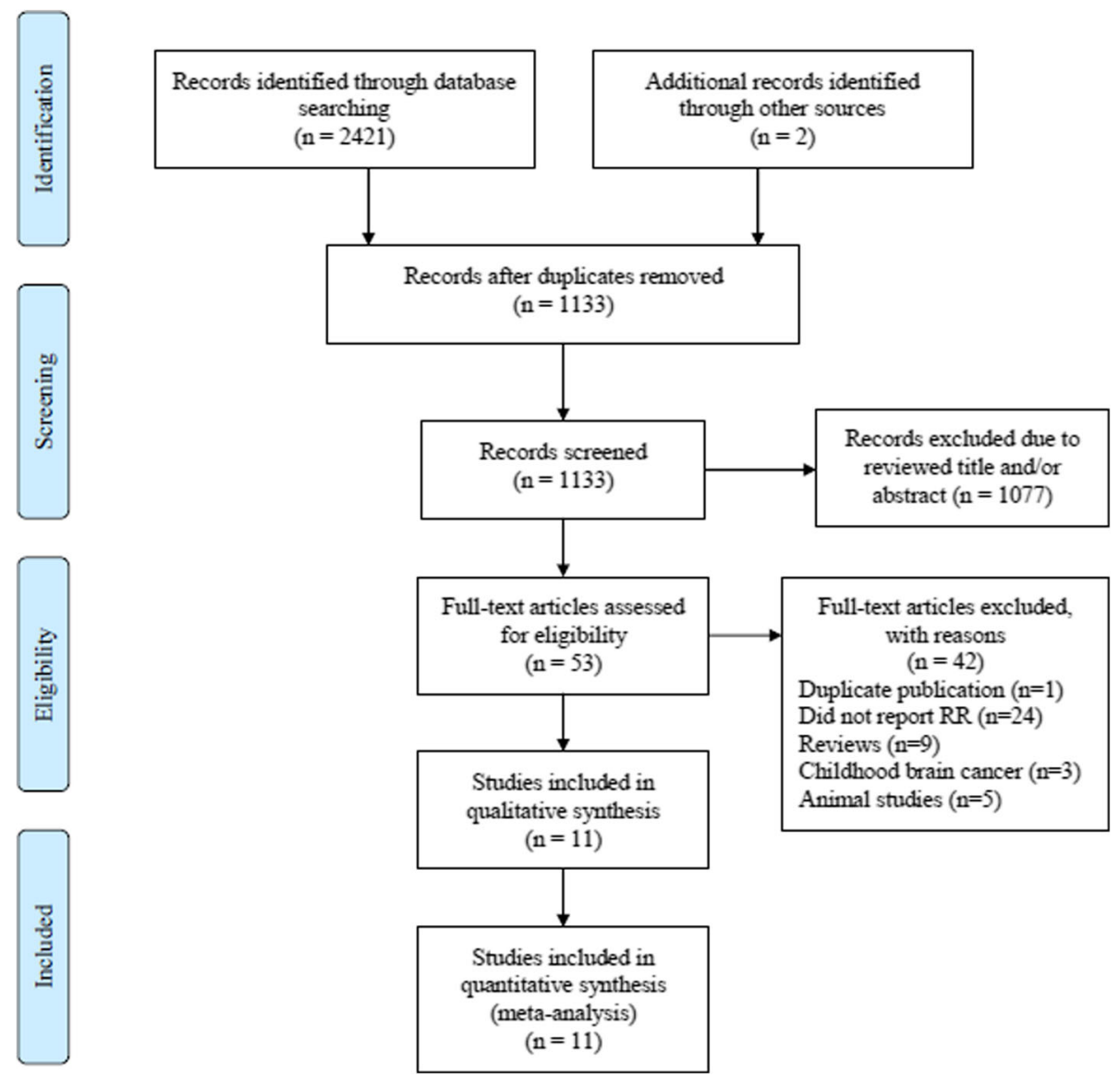

Fig. 1 Flow chart of meta-analysis for exclusion/inclusion of studies

location, we found a statistically significant protective effect of tea consumption and the risk of brain cancer in American populations $(\mathrm{RR}=0.798,95 \% \quad \mathrm{CI}=0.646-$ 0.986), instead of other populations. Detailed results are shown in Table 2.

Based on Egger's test $(P=0.735)$ and funnel plot (Additional file 2: Figure S2), there existed no publication bias between tea consumption and brain cancer risk. Sensitivity analysis was done and the pooled $\mathrm{RR}$ ranged from $0.863(95 \% \mathrm{CI}=0.699-1.067)$ to $0.947(95 \% \mathrm{CI}=0.763-1.176)$.

Coffee plus tea consumption and the risk of brain cancer Four studies [25, 29-31] were performed to assess the association between coffee plus tea consumption and the risk of brain cancer. Figure 4 showed that the RR was 0.684 (95\% CI $=0.481-0.975)$ when compared the highest versus the lowest category consumption of coffee plus tea.

\section{Discussion}

This meta-analysis included 11 publications involving 2583 cases and 1,684,262 participants to assess the association of coffee consumption, tea consumption, and coffee plus tea consumption on the risk of brain cancer. We also performed subgroup analyses by study design and geographic location to further explore the association between coffee and tea consumption and the risk of brain cancer.

There were some differences between our meta-analysis and the study by Malerba et al. [18]. First, Malerba et al. included six studies for coffee consumption, four studies for tea consumption, three studies for coffee plus tea consumption to assess the risk of adult glioma. However, we included 11 studies for coffee consumption, 8 studies for tea consumption, and 4 studies for coffee plus tea consumption, which was more than Malerba et al. Second, the results in our analysis suggested the highest versus the lowest categories coffee consumption and coffee plus tea consumption were inversely associated with the risk of brain cancer, which was different from the results of Malerba et al. However, we got a consistent result for tea consumption and the risk of brain cancer with them.

Tea and coffee are rich in polyphenols including phenolic acids and flavonoids [34], which are known for their 


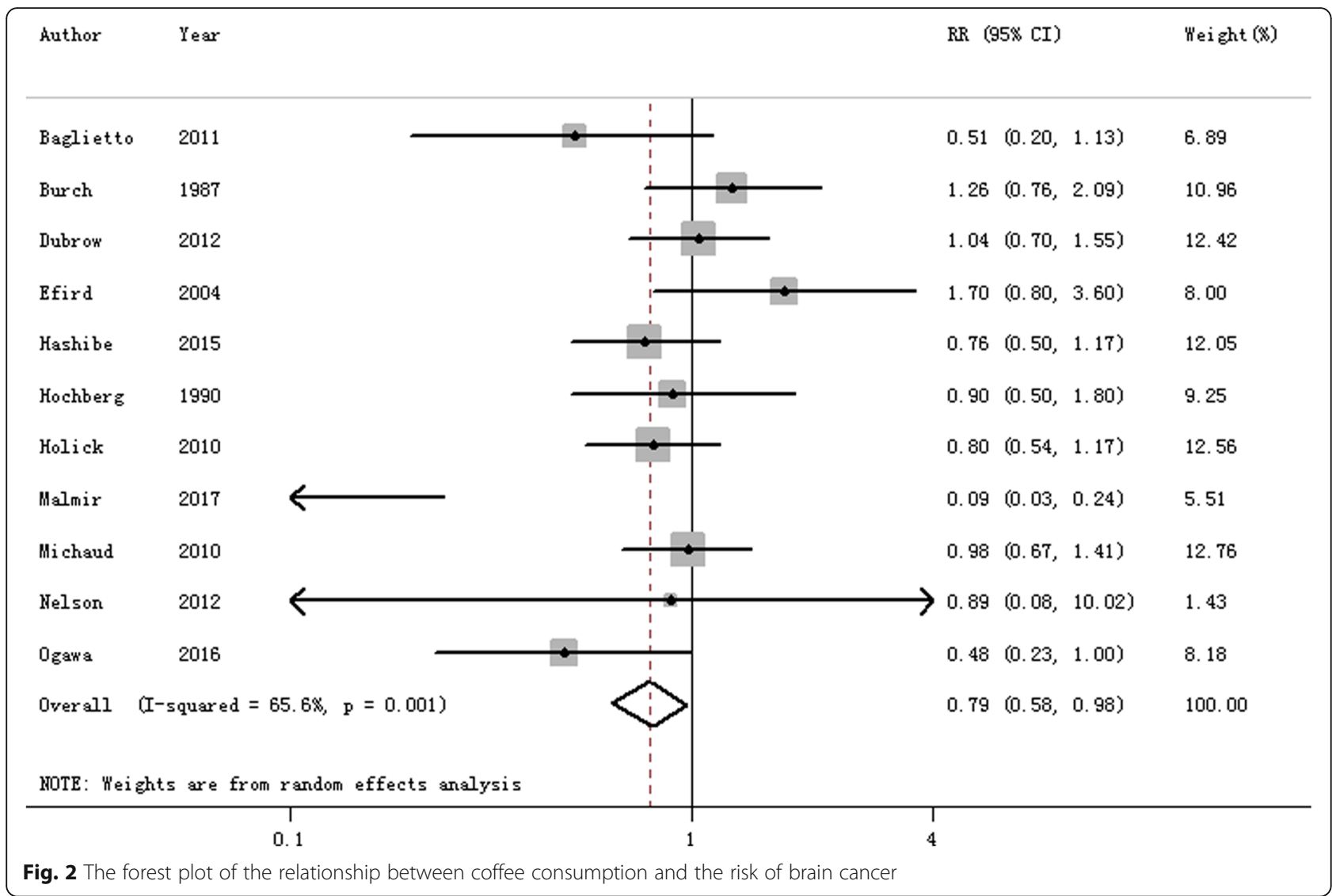

antioxidant activity, regulation of heterogeneous metabolite enzymes, and inhibition of tumor promotion [35], and have been shown to prevent cancer [36, 37]. Furthermore, diterpenes and caffeic acid in coffee could protect against cancer [38]. However, different tea consumed (such as green tea or black tea) and different coffee brewing method may vary on the effect of cancer [39]. We did not analyze the detailed effect about the account type of tea consumed and coffee brewing method on brain cancer due to the limited information in the individual study. Therefore, further researches are warranted to explore the potential association about them.
Sensitivity analysis for coffee and tea consumption and the risk of brain cancer was performed. For coffee consumption and brain cancer risk, the association changed from being statistically significant to not statistically significant when removed the study by Malmir et al. 2017 $(R R=0.905,95 \% C I=0.754-1.088)$. Therefore, the result for coffee consumption and the risk of brain cancer was not stable. Future studies with large participants are warranted to further confirm this association. For tea consumption and the risk of brain cancer, the association was not significant when removed a single study one by one, with pooled RR ranged from $0.863(95 \% \mathrm{CI}=0.699-1.067)$

Table 2 Summary risk estimates of the association between tea and coffee consumption and brain cancer risk

\begin{tabular}{|c|c|c|c|c|c|c|c|c|}
\hline \multirow[t]{2}{*}{ Subgroups } & \multicolumn{4}{|c|}{ Tea consumption (highest vs. lowest category) } & \multicolumn{4}{|c|}{ Coffee consumption (highest vs. lowest category) } \\
\hline & Studies, $n$ & $\mathrm{RR}(95 \% \mathrm{Cl})$ & $P^{2}(\%)$ & $P_{\text {heterogeneity }}$ & Studies, $n$ & $\mathrm{RR}(95 \% \mathrm{Cl})$ & $P^{2}(\%)$ & $\bar{P} P_{\text {heterogeneity }}$ \\
\hline All studies & 8 & $0.897(0.739-1.088)$ & 29.9 & 0.189 & 11 & $0.785(0.580-0.984)$ & 65.6 & 0.001 \\
\hline Glioma & 7 & $0.846(0.683-1.047)$ & 24.6 & 0.241 & 10 & $0.760(0.548-0.972)$ & 63.9 & 0.003 \\
\hline Cohort & 6 & $0.891(0.755-1.051)$ & 0.0 & 0.471 & 8 & $0.858(0.700-0.992)$ & 20.1 & 0.270 \\
\hline Case-control & 2 & $0.658(0.199-2.179)$ & 81.5 & 0.020 & 3 & $0.507(0.142-1.810)$ & 90.1 & $<0.001$ \\
\hline America & 4 & $0.798(0.646-0.986)$ & 0.0 & 0.595 & 6 & $0.912(0.740-1.124)$ & 0.0 & 0.520 \\
\hline Europe & 2 & $1.080(0.828-1.410)$ & 0.0 & 0.792 & 2 & $1.070(0.793-1.444)$ & 0.0 & 0.433 \\
\hline Asia & 2 & $0.643(0.205-2.016)$ & 79.9 & 0.026 & 2 & $0.217(0.042-0.896)$ & 84.9 & 0.010 \\
\hline Oceania & - & - & - & - & 1 & - & - & - \\
\hline
\end{tabular}




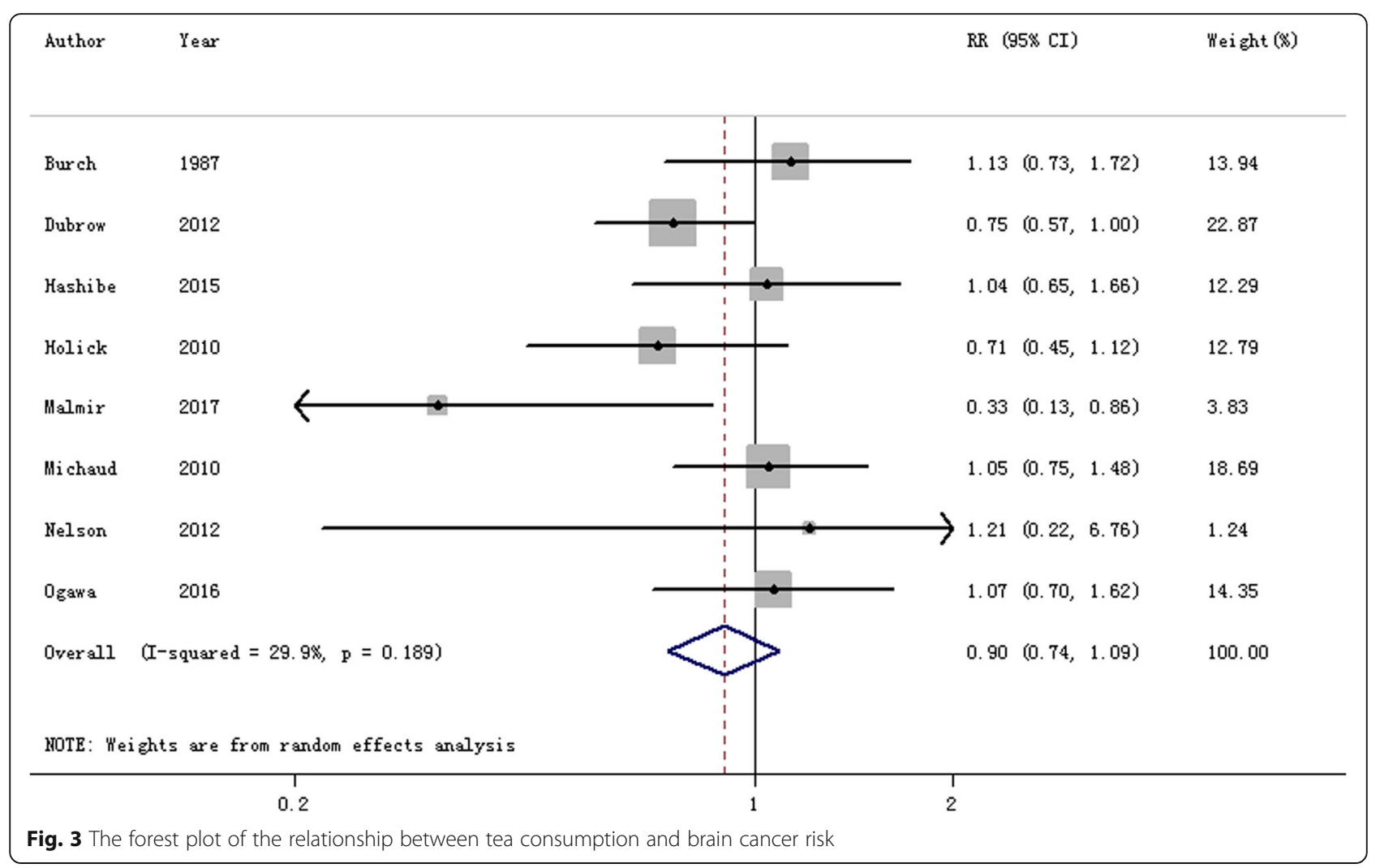

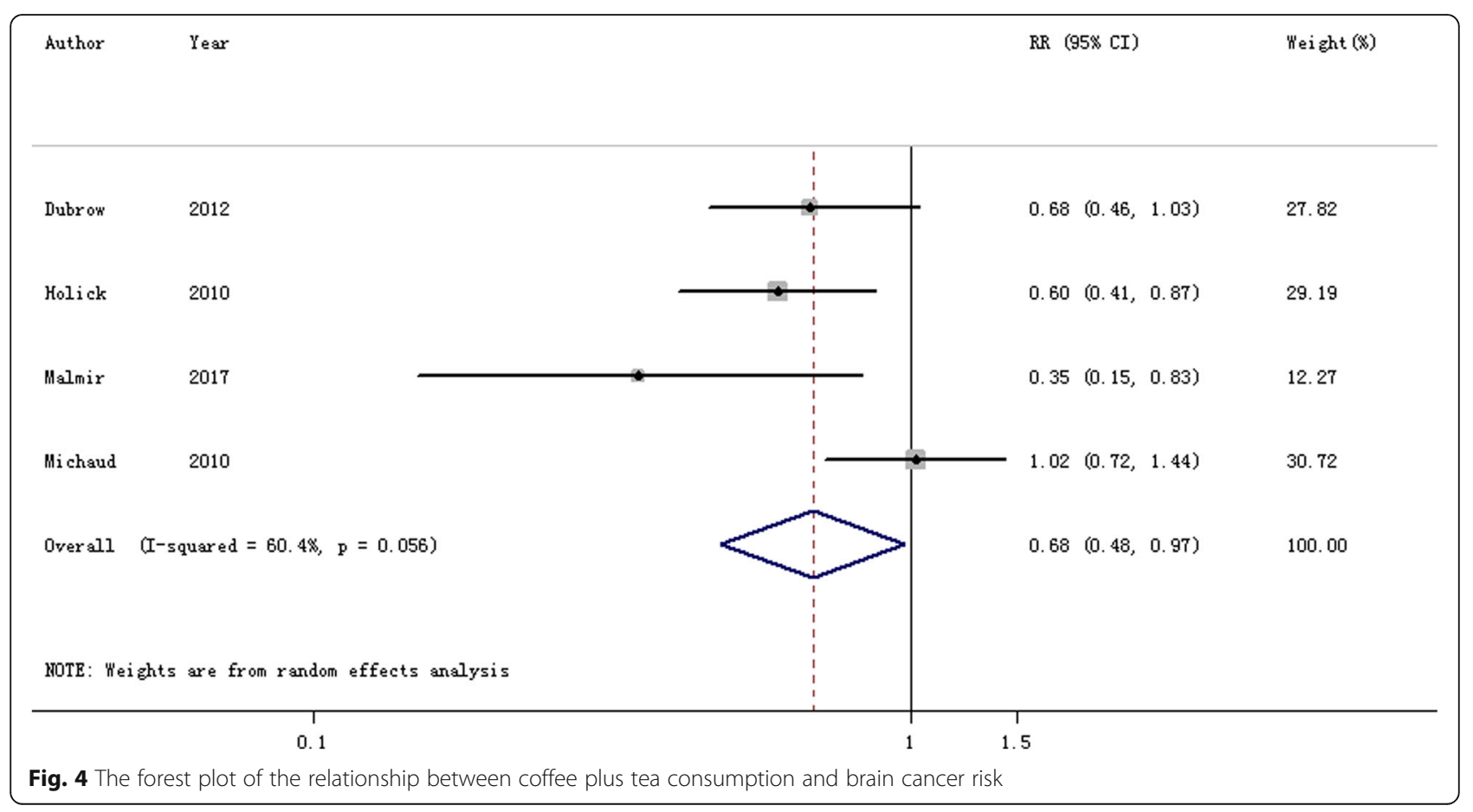


to 0.947 ( $95 \% \mathrm{CI}=0.763-1.176)$. For coffee plus tea consumption and the risk of brain cancer, the pooled RR changed to $0.754(95 \% \mathrm{CI}=0.543-1.045)$ when removed the study by Malmir et al. 2017. Thus, more relevant studies about coffee plus tea consumption and the risk of brain cancer are needed.

Some limitations existed in our meta-analysis. First, high between-study heterogeneity existed in some results. Although meta-regression analysis was performed to explore the sources of this high between-study heterogeneity, we could not find the detailed sources of heterogeneity due to stratified analysis and meta-regression analysis concerning the relationship between coffee consumption and the risk of brain cancer. On the other hand, we used a random-effects model in all the results, which had a wider CI than the fixed-effects model. Thus, random-effects could obtain a more conservative result. Second, 3 of the 11 studies were case-control design, which could lead to some recalling bias, selective bias, and so on. However, case-control studies could also explain the relationship between coffee and tea consumption and the risk of brain cancer. Third, we could not perform the subgroup analysis by sex or lifestyle due to the limited information in each individual study. Considering sex and lifestyle may be a risk factor for coffee and/or tea consumption, future studies with detailed information about sex and lifestyle are warranted to further explore the association between coffee or tea consumption and risk of brain cancer. Fourth, the range of years in coffee or tea consumption may play a different role in the risk of brain cancer due to cancer maybe consists of various stages during aging [40]. However, the information about the range of years about coffee and tea consumption in each individual study was limited.

\section{Conclusions}

Findings from this study suggested that higher consumption of coffee may contribute to the lower development of brain cancer in Asian populations. Tea consumption had an inverse association for the risk of brain cancer in American populations, instead of other populations. As some limitations existed in our study, future studies with detailed information about sex, lifestyle, and some other related factors are warranted to further explore the association between coffee or tea consumption and risk of brain cancer.

\section{Additional files}

Additional file 1: Figure S1. Funnel plot for the analysis of publication bias between coffee consumption and brain cancer risk. (TIF $40 \mathrm{~kb}$ )

Additional file 2: Figure S2. Funnel plot for the analysis of publication bias between tea consumption and brain cancer risk. (TIF 39 kb)
Abbreviations

$\mathrm{Cl}$ : Confidence interval; OR: Odds ratio; RR: Relative risk

\section{Acknowledgements}

None

Funding

None.

Availability of data and materials

The tables and figures supporting the conclusions of this article are included within the article.

Author's contributions

YS conceived and designed the study. YS, ZYW, and YYJ participated in data collecting. JG analyzed data. YS and ZYW commented on drafts of the paper. All authors read and approved the final manuscript.

Ethics approval and consent to participate

Not applicable.

Consent for publication

All authors consented for publication.

Competing interests

The authors declare that they have no competing interests.

\section{Publisher's Note}

Springer Nature remains neutral with regard to jurisdictional claims in published maps and institutional affiliations.

\section{Author details}

'Department of Neurology, Tianjin First Center Hospital, No. 24, Fukang Road, Nankai District, Tianjin 300192, China. ${ }^{2}$ Department of General Surgery,

Tianjin First Center Hospital, Tianjin 300192, China.

Received: 17 January 2019 Accepted: 7 March 2019

Published online: 15 March 2019

\section{References}

1. Li WF, Niu C, Shakir TM, et al. An evidence-based approach to assess the accuracy of intravoxel incoherent motion imaging for the grading of brain tumors. Medicine (Baltimore). 2018;97:e13217.

2. Daumas-Duport C, Scheithauer B, O'Fallon J, et al. Grading of astrocytomas. A simple and reproducible method. Cancer. 1988;62:2152-65.

3. Li Y. Association between fruit and vegetable intake and risk for glioma: a meta-analysis. Nutrition. 2014;30:1272-8.

4. Lian W, Wang R, Xing B, et al. Fish intake and the risk of brain tumor: a meta-analysis with systematic review. Nutr J. 2017;16:1.

5. Lv W, Zhong X, Xu L, et al. Association between dietary vitamin a intake and the risk of glioma: evidence from a meta-analysis. Nutrients. 2015;7: 8897-904.

6. Zhou S, Wang $X$, Tan $Y$, et al. Association between vitamin C intake and glioma risk: evidence from a meta-analysis. Neuroepidemiology. 2015:44:39-44.

7. Kyritsis AP, Bondy MLand Levin VA. Modulation of glioma risk and progression by dietary nutrients and antiinflammatory agents. Nutr Cancer. 2011;63:174-84

8. Horisaki K, Takahashi K, Ito H, et al. A dose-response meta-analysis of coffee consumption and colorectal Cancer risk in the Japanese population: application of a cubic-spline model. J Epidemiol. 2018;28:503-9.

9. Lukic M, Guha N, Licaj I, et al. Coffee drinking and the risk of endometrial Cancer: an updated meta-analysis of observational studies. Nutr Cancer. 2018;70:513-28.

10. Lafranconi A, Micek A, Galvano F, et al. Coffee decreases the risk of endometrial Cancer: a dose-response meta-analysis of prospective cohort studies. Nutrients. 2017;9. https://doi.org/10.3390/nu9111223.

11. Ni CX, Gong H, Liu Y, et al. Green tea consumption and the risk of liver Cancer: a meta-analysis. Nutr Cancer. 2017;69:211-20.

12. Huang $Y Q, L$ L X, Min H, et al. Green tea and liver cancer risk: a meta-analysis of prospective cohort studies in Asian populations. Nutrition. 2016;32:3-8. 
13. Zhan X, Wang J, Pan S, et al. Tea consumption and the risk of ovarian cancer: a meta-analysis of epidemiological studies. Oncotarget. 2017;8 37796-806.

14. Huang $Y$, Chen $H$, Zhou L, et al. Association between green tea intake and risk of gastric cancer: a systematic review and dose-response meta-analysis of observational studies. Public Health Nutr. 2017;20:3183-92.

15. Zhou H, Wu W, Wang F, et al. Tea consumption is associated with decreased risk of oral cancer: a comprehensive and dose-response metaanalysis based on 14 case-control studies (MOOSE compliant). Medicine (Baltimore). 2018;97:e13611.

16. Wang $W$, Yang Y, Zhang W, et al. Association of tea consumption and the risk of oral cancer: a meta-analysis. Oral Oncol. 2014;50:276-81.

17. Zhou Q, Li H, Zhou JG, et al. Green tea, black tea consumption and risk of endometrial cancer: a systematic review and meta-analysis. Arch Gynecol Obstet. 2016:293:143-55.

18. Malerba S, Galeone C, Pelucchi C, et al. A meta-analysis of coffee and tea consumption and the risk of glioma in adults. Cancer Causes Control. 2013; 24:267-76.

19. Higgins JP, Thompson SG, Deeks JJ, et al. Measuring inconsistency in metaanalyses. BMJ. 2003;327:557-60.

20. Higgins JP, Thompson SG. Quantifying heterogeneity in a meta-analysis. Stat Med. 2002;21:1539-58.

21. Egger M, Davey Smith G, Schneider M, et al. Bias in meta-analysis detected by a simple, graphical test. BMJ. 1997;315:629-34.

22. Begg CBand Mazumdar M. Operating characteristics of a rank correlation test for publication bias. Biometrics. 1994;50:1088-101.

23. Baglietto L, Giles GG, English DR, et al. Alcohol consumption and risk of glioblastoma; evidence from the Melbourne collaborative cohort study. Int J Cancer. 2011;128:1929-34.

24. Burch JD, Craib KJ, Choi BC, et al. An exploratory case-control study of brain tumors in adults. J Natl Cancer Inst. 1987;78:601-9.

25. Dubrow R, Darefsky AS, Freedman ND, et al. Coffee, tea, soda, and caffeine intake in relation to risk of adult glioma in the $\mathrm{NIH}$-AARP diet and health study. Cancer Causes Control. 2012;23:757-68.

26. Efird JT, Friedman GD, Sidney $\mathrm{S}$, et al. The risk for malignant primary adultonset glioma in a large, multiethnic, managed-care cohort: cigarette smoking and other lifestyle behaviors. J Neuro-Oncol. 2004;68:57-69.

27. Hashibe M, Galeone C, Buys SS, et al. Coffee, tea, caffeine intake, and the risk of cancer in the PLCO cohort. Br J Cancer. 2015;113:809-16.

28. Hochberg F, Toniolo P, Cole P, et al. Nonoccupational risk indicators of glioblastoma in adults. J Neuro-Oncol. 1990;8:55-60.

29. Holick CN, Smith SG, Giovannucci E, et al. Coffee, tea, caffeine intake, and risk of adult glioma in three prospective cohort studies. Cancer Epidemiol Biomark Prev. 2010;19:39-47.

30. Malmir H, Shayanfar M, Mohammad-Shirazi M, et al. Tea and coffee consumption in relation to glioma: a case-control study. Eur J Nutr. 2017. [Epub ahead of print].

31. Michaud DS, Gallo V, Schlehofer B, et al. Coffee and tea intake and risk of brain tumors in the European prospective investigation into Cancer and nutrition (EPIC) cohort study. Am J Clin Nutr. 2010;92:1145-50.

32. Nelson JS, Burchfiel CM, Fekedulegn D, et al. Potential risk factors for incident glioblastoma multiforme: the Honolulu heart program and Honolulu-Asia aging study. J Neuro-Oncol. 2012;109:315-21.

33. Ogawa T, Sawada N, Iwasaki M, et al. Coffee and green tea consumption in relation to brain tumor risk in a Japanese population. Int J Cancer. 2016;139:2714-21.

34. Scalbert A, Williamson G. Dietary intake and bioavailability of polyphenols. J Nutr. 2000;130:2073S-85S

35. Frei B, Higdon JV. Antioxidant activity of tea polyphenols in vivo: evidence from animal studies. J Nutr. 2003;133:3275S-84S.

36. Yang CS, Maliakal P, Meng X. Inhibition of carcinogenesis by tea. Annu Rev Pharmacol Toxicol. 2002:42:25-54.

37. Ju J, Lu G, Lambert JD, et al. Inhibition of carcinogenesis by tea constituents. Semin Cancer Biol. 2007;17:395-402.

38. Cavin C, Holzhaeuser D, Scharf G, et al. Cafestol and kahweol, two coffee specific diterpenes with anticarcinogenic activity. Food Chem Toxicol. 2002:40:1155-63.

39. Sachinidis A, Seul C, Seewald S, et al. Green tea compounds inhibit tyrosine phosphorylation of PDGF beta-receptor and transformation of A172 human glioblastoma. FEBS Lett. 2000;471:51-5.

40. Baker DJ, Peleg S. Biphasic modeling of mitochondrial metabolism dysregulation during aging. Trends Biochem Sci. 2017:42:702-11.

\section{Ready to submit your research? Choose BMC and benefit from:}

- fast, convenient online submission

- thorough peer review by experienced researchers in your field

- rapid publication on acceptance

- support for research data, including large and complex data types

- gold Open Access which fosters wider collaboration and increased citations

- maximum visibility for your research: over $100 \mathrm{M}$ website views per year

At BMC, research is always in progress.

Learn more biomedcentral.com/submissions 